\title{
Electrostatic Activation of Tetrazoles
}

\author{
Vincent Doan, Benjamin B. Noble, † Michelle L. Coote* \\ ARC Centre of Excellence for Electromaterials Science, Research School of Chemistry, Australian National University, ACT \\ 2601, Australia
}

*Correspondence: michelle.coote@anu.edu.au

\begin{abstract}
Photoactivation of tetrazoles to form nitrile imines primed for 1,3-dipolar cycloaddition reactions is of widespread utility in chemistry. In contrast, the corresponding thermal reactions usually possess prohibitively high barriers and have garnered significantly less attention. Here computational chemistry at the M06-2X/6-31+G(d,p) level of theory with SMD solvent corrections, is used to show that these thermal activation barriers can be significantly reduced through the use of non-conjugated charged functional groups (CFGs). For 2,5-dimethyl-tetrazole, a positive CFG on the N-methyl (2-position) lowers the fragmentation barrier by around $80 \mathrm{~kJ} \mathrm{~mol}^{-1}$ in the gas-phase, while a negative charge has a smaller opposite effect. These CFG effects remain significant even in polar solvent, with barrier lowering on the order of $30 \mathrm{~kJ} \mathrm{~mol}^{-1}$ in dimethyl sulfoxide and acetonitrile. In practical terms, the positive CFG decreases the fragmentation half-life of 2,5-dimethyl-tetrazole in refluxing o-xylene from 300,000 years to 1 week. While the resulting nitrile imine is stabilized, its subsequent 1,3-cycloaddition with $\mathrm{N}$-methylmaleimide remains highly facile. Electrostatic effects on a range of 2-phenyl-5-methyltetrazoles, 2-methyl-5-phenyl-tetrazoles and 2,5-diphenyl-tetrazoles follow similar trends and are explicable largely in terms of the stabilization of the developing dipole in the transition state.
\end{abstract}

\section{INTRODUCTION}

Tetrazoles are an important class of poly-aza-heteroxyclic compounds, used in functional materials, ${ }^{1}$ as catalysts, ${ }^{2}$ and as bioisosteres, ${ }^{3}$ among other applications. ${ }^{4}$ They can undergo thermal- or photo-activation to generate nitrile imines; important intermediates for five membered heterocyclic synthesis in organic chemistry. ${ }^{5}$ Of particular importance is tetrazole-alkene 1,3 dipolar cycloaddition, which was first reported by Huisgen et al. in the 1960s. ${ }^{67}$ In this process, the tetrazole eliminates nitrogen under photochemical or thermal stimuli to form a nitrile imine, capable of undergoing 1,3 dipolar cycloaddition to double bonds (Scheme 1). Thermally, nitrile imine formation has a gas-phase Arrhenius barrier of the order of $200 \mathrm{~kJ} \mathrm{~mol}^{-1} 8$ (see also Ref. 9 and 10). Consequently, temperatures of $200{ }^{\circ} \mathrm{C}$ or more are typically required for activation, ${ }^{11-14}$ which limits synthetic utility. In contrast, photochemical activation has found widespread applications as a photoligation reaction in materials synthesis ${ }^{15-18}$ and bioorthogonal chemistry. ${ }^{19,} 20$ Under thermal conditions, nitrile imines for synthesis are normally generated via other methods, such as from the reaction of aldehydes with $\mathrm{N}_{1}$-alkyl- $\mathrm{N}_{2}-$ acyl hydrazines. ${ }^{21}$

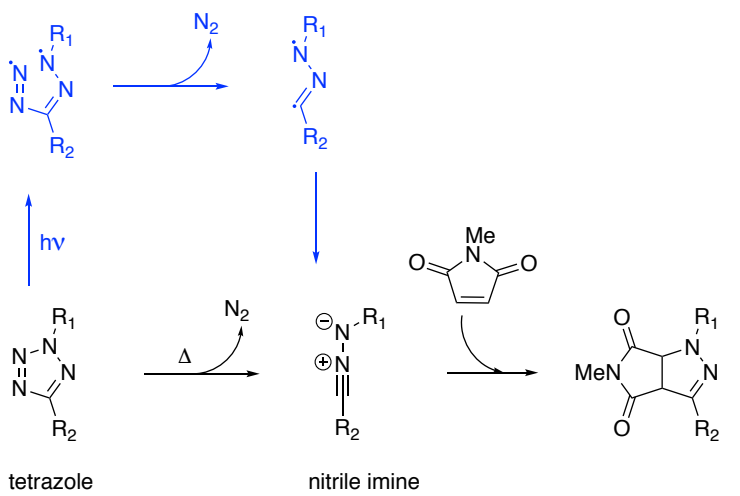

Scheme 1. Thermal and photochemical activation of a tetrazole to form a nitrile imine and its subsequent 1,3 dipolar cycloaddition to $\mathrm{N}$-methyl maleimde.

While the photochemical activation of tetrazoles is undoubtedly of widespread utility, it would nonetheless be useful to develop methods for thermally generating nitrile imines from tetrazoles under milder conditions for synthesis. One possible strategy for this is to utilize electric fields. The use of electrostatics for catalyzing nonredox chemical reactions has been increasingly attracting attention of chemists across diverse disciplines. ${ }^{22,23}$ Electrostatic catalysis makes use of an oriented electric field to stabilize or destabilize polar transition states and products, even for formally covalent species, by influencing the stability of their minor charged-separated resonance contributors. ${ }^{24}$ This allows the electric field to 
kinetically and/or thermodynamically favor or disfavor certain reaction pathways over others. A promising strategy for harnessing such effects is via the use of remote acids or bases, placed on the substrate, auxiliary or catalyst. By choosing their position carefully, the field be optimally oriented relative to the reaction center, while the charge and hence field can be switched on or off through simple $\mathrm{pH}$ changes. ${ }^{25-27}$

Previously, it has been shown that both external electric fields ${ }^{28,29}$ and the electric fields from remote charged functional groups (CFGs), ${ }^{30-32}$ on the substrate or external catalyst, can catalyze $4+2$ cycloadditions, as well as modify their regio- and diastereoselectivity. Moreover, in a computational study directly related to the present work, Datta and co-workers have recently shown that the reactivity of nitrile imines in cycloaddition with alkynes can be catalyzed by as much as $25 \mathrm{~kJ} \mathrm{~mol}^{-1}$ with external electric fields. ${ }^{33}$ These promising results suggest that thermally promoting nitrile imine-based click reactions is feasible. Further, Montero-Campillo et al. ${ }^{34}$ showed that the 1,3-dipolar cycloaddition reaction of $\mathrm{N}_{2}$ with nitrile imines (i.e., the reverse of the reactions studied here) is promoted by Lewis acids. Although neutral species were used in that work, they are nonetheless polar and their success suggests that electrostatic effects, at least in part, are stabilizing the transition state. Inspired by these results, here we utilize use computational chemistry to ascertain if remote CFGs can electrostatically activate tetrazoles under milder conditions, while retaining their reactivity in subsequent 1,3 dipolar cycloadditions.

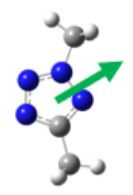

2.7 D

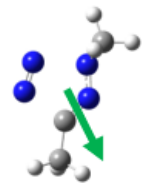

$3.0 \mathrm{D}$

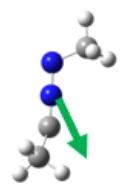

2.8 D

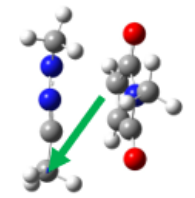

$3.4 \mathrm{D}$

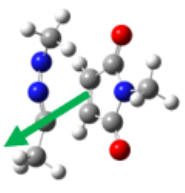

3.7 D

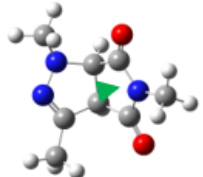

$1.0 \mathrm{D}$

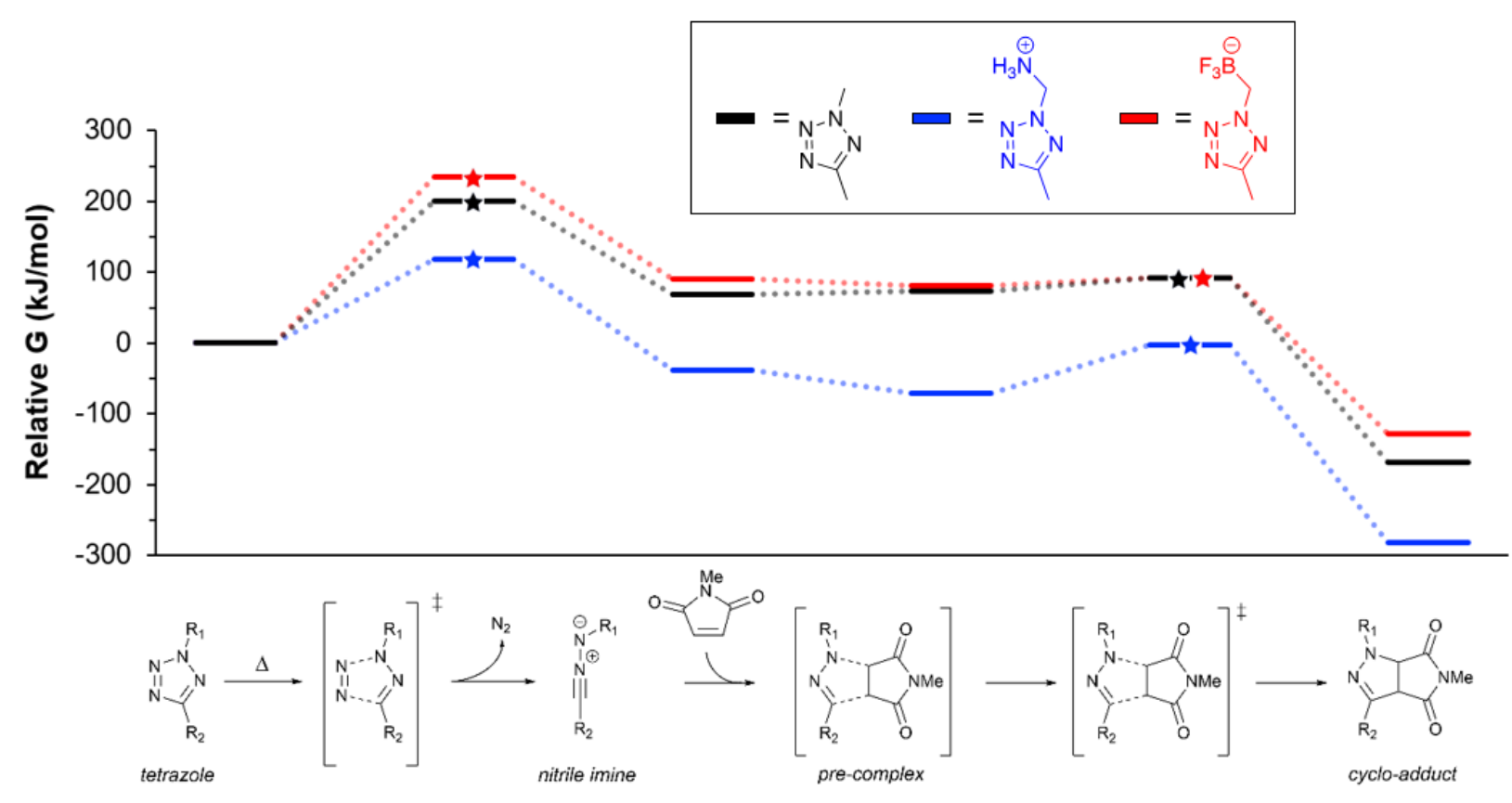

Reaction Coordinate

Figure 1. Gibbs free energy surface $\left(25^{\circ} \mathrm{C}, \mathrm{kJ} \mathrm{mol}{ }^{-1}\right)$ for the thermal reaction of 2,5-dimethyl-tetrazole $\left(\mathrm{R}_{1}=\mathrm{CH}_{3}\right.$ and $\left.\mathrm{R}_{2}=\mathrm{CH}_{3}\right)$ with $\mathrm{N}$-methylmaleimide in the gas-phase (black line). The blue and red lines show the corresponding reaction when the $\mathrm{N}$ methyl of 2,5-dimethyl-tetrazole is replaced with a positively-charged $\left(\mathrm{R}_{1}=\mathrm{CH}_{2} \mathrm{NH}_{3}{ }^{+}\right.$, blue) and negatively-charged $\left(\mathrm{R}_{1}=\mathrm{CH}_{2} \mathrm{BF}_{3}\right.$ , red) functional group. Respective dipole moments (in Debye) for various species in the neutral 2,5-dimethyl-tetrazole reaction are also shown. The dipole arrows point from regions of negative charge to positive charge. 


\section{RESULTS AND DISCUSSION}

2,5-Dimethyl-tetrazole. We initially examined the simplest compound, 2,5-dimethyl-tetrazole. Figure 1 shows the potential energy surface for its ground-state reaction with $\mathrm{N}$-methylmaleimide, which is a typical coupling partner in applications. Corresponding results when the $\mathrm{N}$-methyl group (2-position) of 2,5-dimethyl-tetrazole is replaced by a negatively charged $\left(\mathrm{CH}_{2} \mathrm{BF}_{3}{ }^{-}\right)$or positively charged $\left(\mathrm{CH}_{2} \mathrm{NH}_{3}{ }^{+}\right)$group are also shown. These groups were chosen as simple models for the electrostatic effect of negatively or positively charged groups, and could be altered for more synthetically convenient charged species (quaternary amines, carboxylic acids, etc.) as required. The linker inhibits $\pi$-conjugation with the reaction center; although hyperconjugation and inductive effects may contribute, previous work on other systems have shown that these are dwarfed by electrostatic effects. ${ }^{35,}{ }^{36}$ Figure 1 also shows the dipole moments of each species in the absence of the CFGs.

As Figure 1 illustrates, inclusion of a remote positive CFG at the $\mathrm{N}$ position dramatically lowers the energetics of the reaction across the entire surface, while a negatively charged group raises it somewhat. The effects are not equal and opposite which is indicative of polarization playing a role, and not unexpected given the extensive $\pi$ system. ${ }^{31,35-37}$ The trends fit with what would be expected based on the underlying dipoles of the various species. In all but the reactant tetrazole, the dipole points towards the carbon methyl substituent, indicating a delta positive charge at this position and a delta negative charge on the nitrogen side. This would naturally be stabilized by the inclusion of a positive CFG at the $\mathrm{N}$ position. Because the dipole direction is reversed for the reagent, the positive CFG destabilizes it, and both reactant destabilization and transition state stabilization, contribute to the lower barrier.

For the subsequent cycloaddition process, the dipole directions remain relatively consistent with that of the nitrile imine. Thus, CFGs effects on cycloaddition largely follow the same trends, though they are smaller and more variable due to cancellation between the reactants and transition state. However, for the $\mathrm{CH}_{2} \mathrm{NH}_{3}{ }^{+}$ substituted nitrile imine, in the case of reactant precomplex other hydrogen-bonding interactions with the carbonyls of $\mathrm{N}$-methyl maleimide lead to additional stabilization. Stabilization of the pre-complex, then raises the subsequent barrier for the cycloaddition somewhat. Nonetheless it remains facile, and the ring-opening remains rate determining. More generally, these problems could be overcome through the use of other charged groups (e.g. quaternary amines).
In solution, the barrier-lowering is smaller due to solvent screening, an effect that increases with polarity of the solvent (see Figure 2). The $82 \mathrm{~kJ} \mathrm{~mol}^{-1}$ barrier reduction in the gas-phase (compared with the corresponding unmodified reaction) drops to $56 \mathrm{~kJ} \mathrm{~mol}^{-1}$ in toluene, $39 \mathrm{~kJ}$ $\mathrm{mol}^{-1}$ in dichloromethane and $33 \mathrm{~kJ} \mathrm{~mol}^{-1}$ in acetonitrile and DMSO. These solvents were chosen to provide a wide range of polarities - in practical systems, other considerations such as solubility and potential side-reactions are important. The reduction in electrostatic effects within polar solvents is due to increased solvent screening of the CFG. The effects are non-monotonic because the polar solvents increase the inherent dipole of the transition state, ${ }^{33}$ which offsets screening to some extent. This interplay between solvent screening and polarizability has also been observed for other electrostatically catalyzed reactions..$^{30}$ Electrostatic effects on the barrier in the various solvents with both positive or negatively CFGs are almost perfectly correlated with the corresponding effects on the reaction energy $\left(R^{2}=0.98\right)$, consistent with the Bell-Evans-Polanyi rule. This is because the transition state and product nitrile imine have similar dipoles

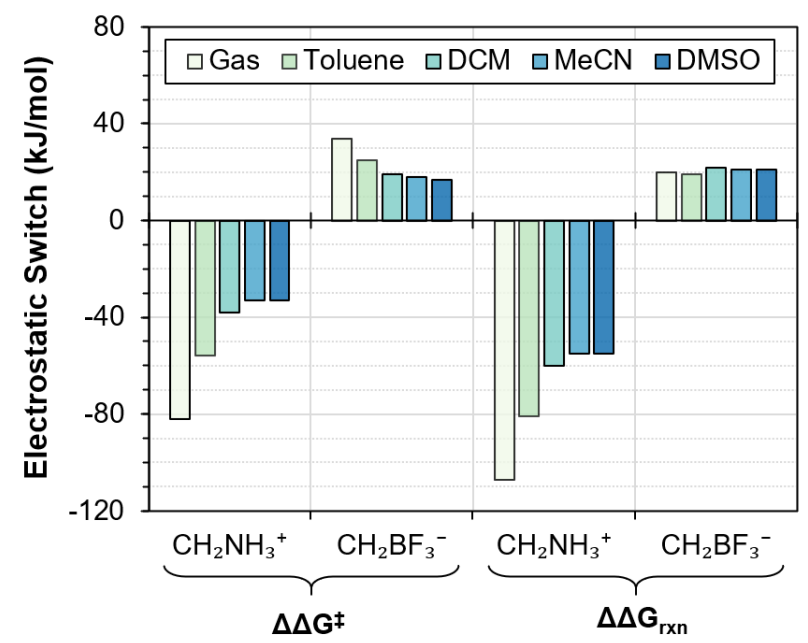

Figure 2. Effect of solvent on the difference in the Gibbs free energy barrier height and reaction energy $\left(25^{\circ} \mathrm{C}\right.$, kJ $\left.\mathrm{mol}^{-1}\right)$ for dimethyl-tetrazole ring-opening in the presence of positively $\left(\mathrm{CH}_{2} \mathrm{NH}_{3}{ }^{+}\right)$and negatively $\left(\mathrm{CH}_{2} \mathrm{BF}_{3}{ }^{-}\right)$charged functional groups in the 2-position $\left(\mathrm{R}_{1}\right.$ in Figure 1$)$. Tol = toluene, $\mathrm{DCM}=$ dichloromethane, $\mathrm{MeCN}=$ acetonitrile and DMSO = dimethyl sulfoxide.

In practical terms, inclusion of a positive CFG drops the (rate determining) gas-phase barrier for nitrile imine formation from an inaccessible $200 \mathrm{~kJ} \mathrm{~mol}^{-1}$ to $118 \mathrm{~kJ} \mathrm{~mol}^{-}$ ${ }^{1}$. While this would still afford a half-life of over a year a room temperature, it would be a minute at $100{ }^{\circ} \mathrm{C}$. For 
comparison, the half-life at $100{ }^{\circ} \mathrm{C}$ for the unmodified substrate would be $3 \times 10^{7}$ years. While barrier lowering is smaller in solution, in low polarity solvents, such as toluene, this effect remains large. Thus, for instance, a practical solvent could be o-xylene, which is non-protic and has a similar dielectric constant to toluene, but a higher boiling point $\left(144^{\circ} \mathrm{C}\right)$. Under conditions of refluxing solvent, the barrier for the positively charged species is $\Delta \mathrm{G}^{\ddagger}=153 \mathrm{~kJ} \mathrm{~mol}^{-1}$, which translates to a half-life of 1 week. This timeframe is close to practical and suggests that a viable system would be accessible with minor substituent changes or techniques such as microwave chemistry. In any case, for comparison, the half-life of the unmodified substrate would be $3 \times 10^{5}$ years under the same conditions (i.e. refluxing o-xylene), which highlights the power of electrostatics in promoting previously unfeasible reactions.

While our focus is on the impact of charged groups on the energetics of fragmentation, the charged functional groups also alter the geometry of the resulting nitrile imines. Six fundamental resonance structures have been postulated for nitrile imines (Chart 1). Of these,
Begue et al. ${ }^{38}$ has recently suggested that the propagylic, allenic and carbenic species are predominant, though previous studies also show that 1,3-dipolar resonance plays a significant role, with all four resonance forms required to describe $80 \%$ to $90 \%$ of the electronic properties. ${ }^{39}, 40$ We note that wavefunction stability analysis rules out singlet diradical character for all the species studied here. Figure 3 shows how the structures of the nitrile imines change with substitution and with solvent.

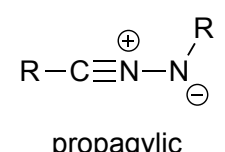<smiles>[R]C=NN=[W]</smiles><smiles>[R][N+]=N[O-]</smiles>
allenic<smiles>[R]C=NN([R])[Ga]O</smiles>

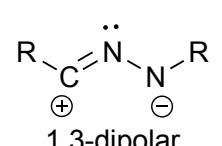
1,3-dipolar<smiles>[R]C(C)=NN([R])C</smiles>

Chart 1. Fundamental resonance structures of nitrile imines.

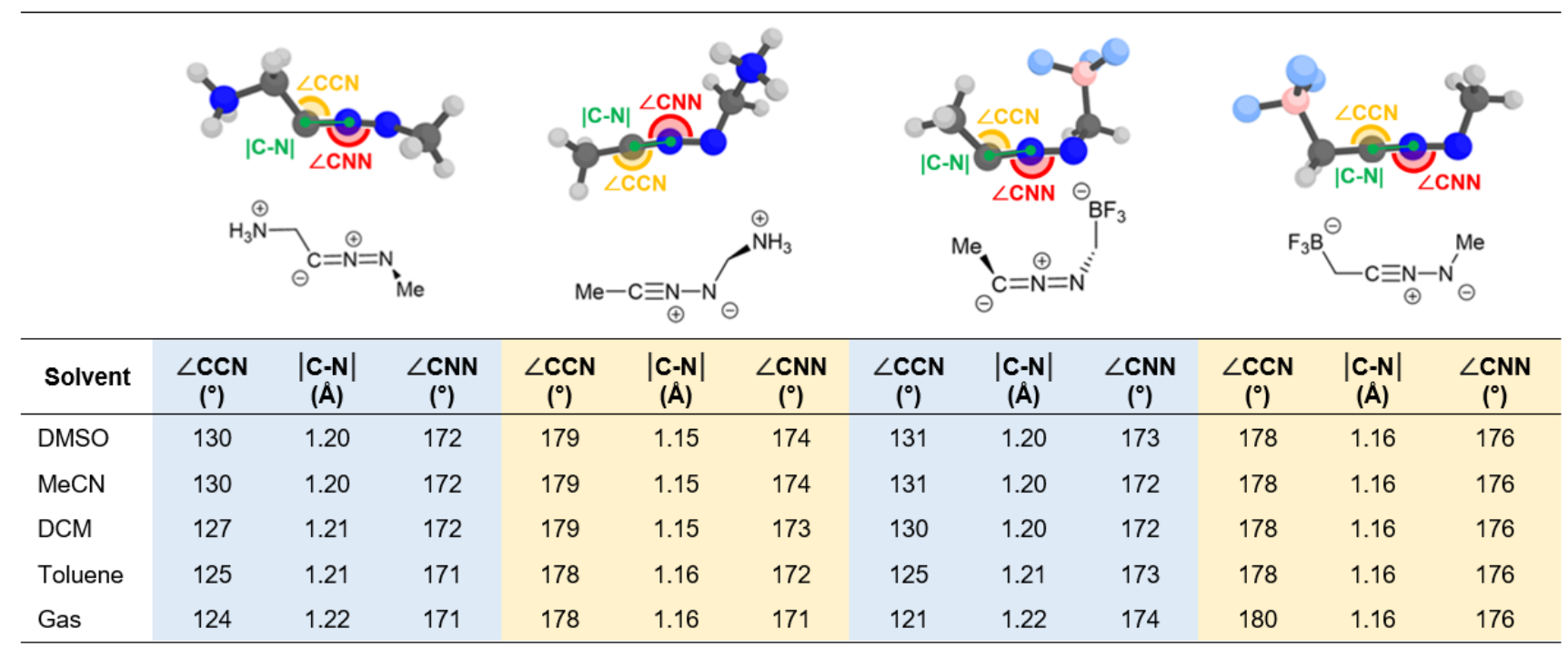

Figure 3. Structures of the nitrile imines as a function of solvent. The dimensions provided are the $\mathrm{C}-\mathrm{N}$ bond length and the $\angle \mathrm{CCN}$ and $\angle \mathrm{CNN}$ angles. When both angles are approximately $180^{\circ}$, the $\mathrm{C}-\mathrm{N}$ bond length is closer to that of a $\mathrm{C} \equiv \mathrm{N}$ bond, and the species has dominant propagylic character (yellow shading). As the $\angle \mathrm{CCN}$ angle approaches $120^{\circ}$, the $\mathrm{C}-\mathrm{N}$ bond lengthens toward a $\mathrm{C}=\mathrm{N}$ bond length and the $\angle \mathrm{CNN}$ remains close to $180^{\circ}$. These features suggest the species has more allenic character (grey shading). 
From Figure 3, it is clear that the nitrile imines studied here fall loosely into two categories: (a) propagylic, as exemplified by $\angle \mathrm{CCN}$ and $\angle \mathrm{CNN}$ angles approaching $180^{\circ}$ and a $\mathrm{C}-\mathrm{N}$ bond length approaching that of a $\mathrm{C} \equiv \mathrm{N}$ bond; $(\mathrm{b})$ allenic, as exemplified by a $\angle \mathrm{CCN}$ angle that approaches $120^{\circ}$, a $\angle \mathrm{CNN}$ angle approaching $180^{\circ}$ and a C-N bond length approaching that of a $\mathrm{C}=\mathrm{N}$ bond. Unsurprisingly, the sign and placement of the CFG determines which of these two structures are favored: a positive CFG on the C-side favors allenic, as does a negative CFG on the N-side. This is because the allenic structure has a formal negative charge on the carbon and positive on the adjacent N. For the propagylic form, the inherent dipole of the nitrile imine reverses and so now it is favored by a negative CFG on the Cside or a positive CFG on the $\mathrm{N}$-side. These results, which are essentially independent of solvent, can be compared with neutral 2,5-dimethyl imine (Figure 4). Now, the allenic form is favored in toluene and the gas phase, consistent with earlier reports, ${ }^{38}$ while the propagylic form is favored in polar solvents, as these stabilize the dipole across the more polarizable NN bond. These stark differences in the structure of the nitrile imines with the different CFGs may have potential implications in controlling selectivity for the 1,3dipolar cycloaddition of asymmetric dipolarophiles.

\begin{tabular}{lccc}
\hline Solvent & $\begin{array}{c}\angle \mathbf{C C N} \\
\left({ }^{\circ}\right)\end{array}$ & $\begin{array}{c}|\mathbf{C}-\mathbf{N}| \\
(\mathbf{A})\end{array}$ & $\begin{array}{c}\angle \mathbf{C N N} \\
\left({ }^{\circ}\right)\end{array}$ \\
\hline DMSO & 179 & 1.16 & 177 \\
MeCN & 179 & 1.16 & 177 \\
DCM & 179 & 1.16 & 177 \\
Toluene & 145 & 1.18 & 173 \\
Gas & 140 & 1.19 & 172 \\
\hline
\end{tabular}

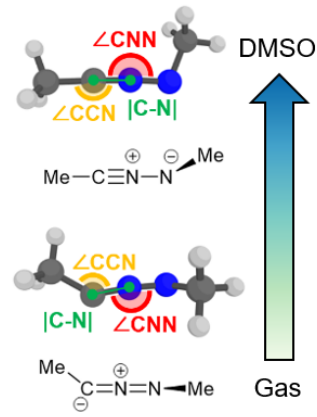

Figure 4. Structures of 2,5-dimethyl nitrile imine as a function of solvent. The dimensions provided are the $\mathrm{C}-\mathrm{N}$ bond length and the $\angle C C N$ and $\angle C N N$ angles. There is a cross over from the allenic form (grey shading) to the propagylic form (yellow shading) as solvent polarity increases.

Phenyl-substituted tetrazoles. In practical applications phenyl-substituted tetrazoles are normally used as they have better photoreactivity due to greater conjugation of the $\pi \pi^{*}$ excited states. Thermally, however, the reactivity of neutral phenyl tetrazoles depends on whether the $\mathrm{N}$ or C-position is substituted. Barriers for 2-phenyl-5-methyl-tetrazole, 2-methyl-5-phenyl-tetrazole and 2,5-diphenyl-tetrazole are shown in Figure 5. Neutral forms, and results with CFGs are included. When the charged group is positioned on the phenyl, it is placed in the paraposition with a $\mathrm{CH}_{2}$ linker. Chart 2 shows the species studied.

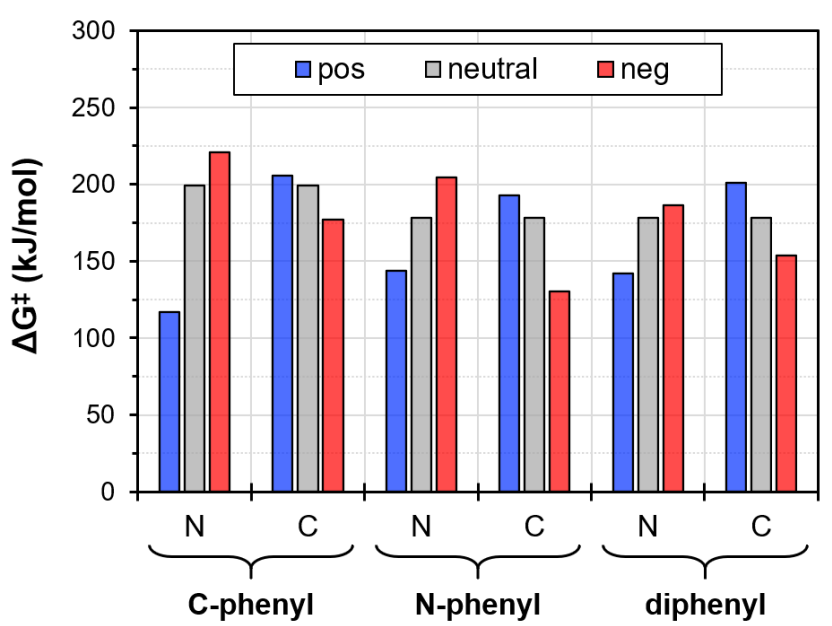

Figure 5. Gibbs free energy barriers (gas, $25^{\circ} \mathrm{C}$, $\mathrm{kJ} \mathrm{mol}^{-1}$ ) for ring-opening of 2-methyl-5-phenyl-tetrazole ("C-phenyl"), 5-methyl-2-phenyl-tetrazole ("N-phenyl"), and 2,5-diphenyl-tetrazole ("diphenyl") and the same species bearing remote CFGs. The nomenclature is explained in Chart 2.
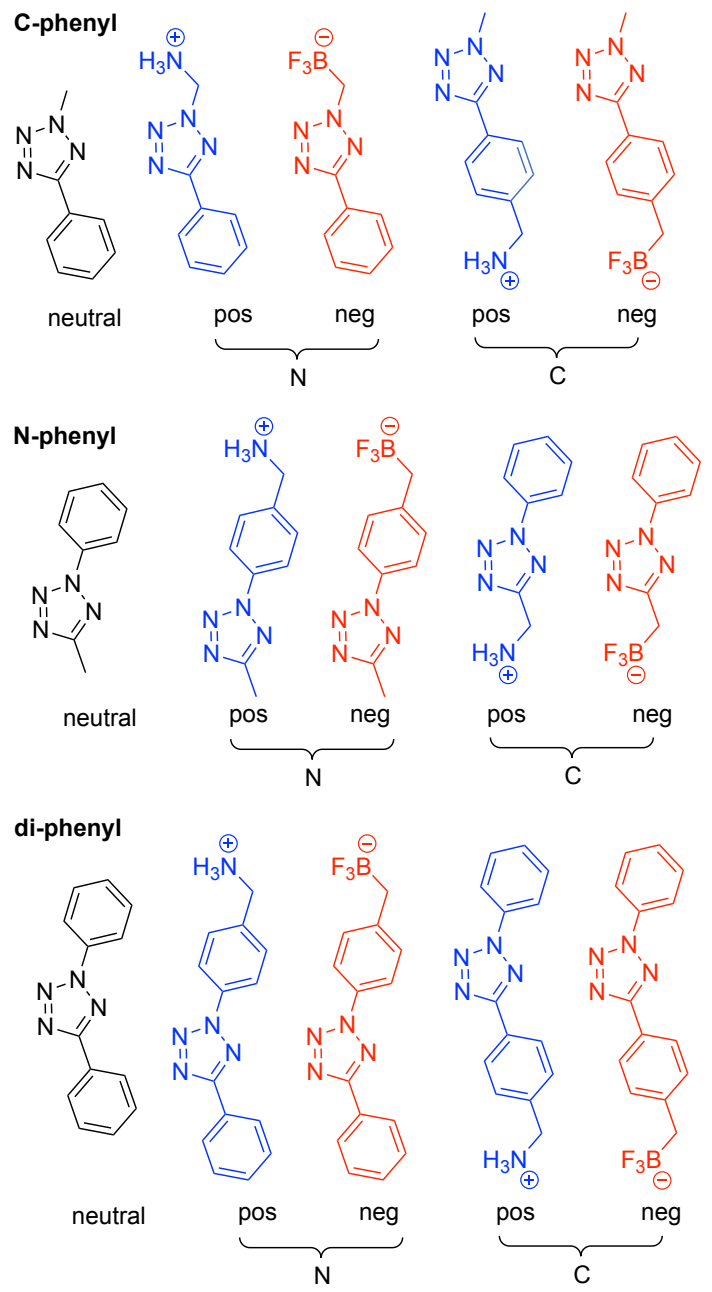

Chart 2. Phenyl-substituted tetrazoles studied. The parent compounds are 2-methyl-5-phenyl-tetrazole (C-phenyl), 5methyl-2-phenyl-tetrazole ( $\mathrm{N}$-phenyl), and 2,5-diphenyl-tetrazole (diphenyl). 
Focusing first on the neutral species, it can be seen that the barrier when the phenyl is substituted at C (2-methyl5-phenyl-tetrazole, $199 \mathrm{~kJ} \mathrm{~mol}^{-1}$ ) is very similar to that obtained for 2,5-dimethyl-tetrazole $\left(200 \mathrm{~kJ} \mathrm{~mol}^{-1}\right)$. In contrast, the barrier for $\mathrm{N}$-phenyl (2-phenyl-5-methyl-tetrazole) is much lower $\left(178 \mathrm{~kJ} \mathrm{~mol}^{-1}\right)$. The barrier for the 2,5-diphenyl-tetrazole is essentially identical to 2-phenyl5-methyl-tetrazole. These trends can be explained through simple resonance arguments. The $\mathrm{N}$-phenyl can delocalize the developing negative charge on the nitrogen into its $\pi$ system. In contrast, due to lack of orbital overlap, the C-phenyl is unable to delocalize the corresponding developing positive charge on carbon without structural changes.

Considering next the charged groups, the trends are inline with the dimethyl-tetrazole results in that a positive CFG on the N-side lowers the barrier, and a negative CFG raises it. As expected, when the CFGs are positioned on the opposite side, the $\mathrm{C}$-side, the reverse trends occur. Solvent effects on the electrostatic effects in the phenyl substituted systems are also largely consistent with the 2,5-dimethyl-tetrazoles, decreasing with the polarity of the solvent as expected. Nonetheless, these effects remain significant even in solvents such as acetonitrile (Figure 6).

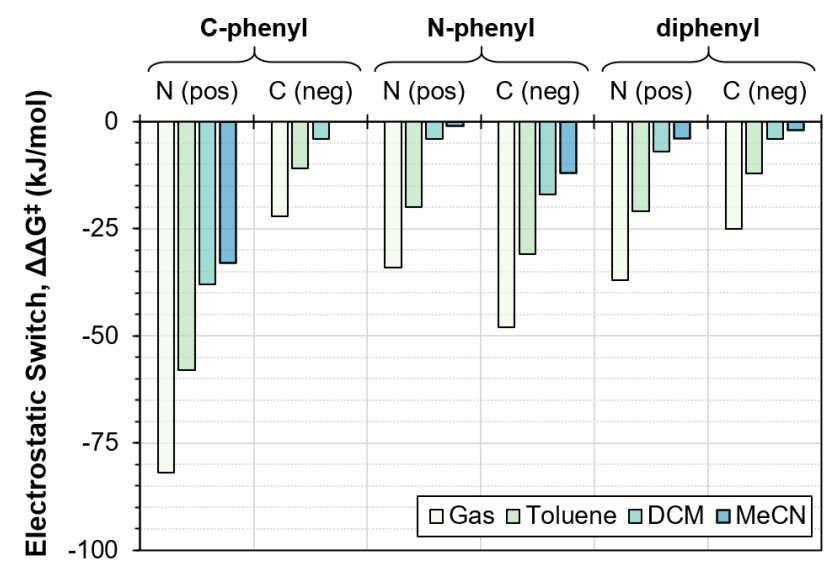

Figure 6. Barrier-lowering effects $\left(25^{\circ} \mathrm{C}, \mathrm{kJ} \mathrm{mol}^{-1}\right)$ of either a positive CFG (pos) or negative CFG (neg) on 2-methyl-5-phenyl-tetrazole ("C-phenyl”), 5-methyl-2-phenyl-tetrazole ("Nphenyl"), and 2,5-diphenyl-tetrazole ("di-phenyl") as a function of the solvent. The nomenclature is explained in Chart 2. For simplicity, only the CFGs that lower the barrier are shown, all results are provided in Table S5 of the Supporting Information. $\mathrm{Tol}=$ toluene, $\mathrm{DCM}=$ dichloromethane and $\mathrm{MeCN}=$ acetonitrile.

The magnitude of barrier-lowering induced by CFG incorporation is more variable across these Ph-substituted systems. In both cases substitution of a stabilizing charge at methyl (i.e. positive at N-methyl, negative at C-methyl), has a greater effect than a stabilizing charge on a phenyl group. This is largely due to a combination of proximity to the reaction center, and alignment to the transition state dipole (Scheme 2). The methyl is both closer and, through bond rotation, better at aligning the charge than the phenyl. Based on the neutral systems, an ortho-substituent in either position would offer better alignment.
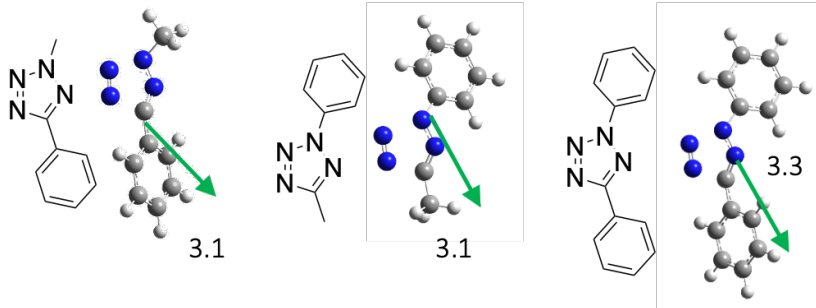

Scheme 2. Dipole moments (in Debye) for the ring-opening transition states of 2-methyl-5-phenyl-tetrazole, 5-methyl2-phenyl-tetrazole and 2,5-diphenyl-tetrazole. The dipole arrows point from regions of negative charge to positive charge.

To test if placement of CFGs at the ortho positions delivered better results, we examined the 5-methyl-2-phenyltetrazole system with a positively charged $\mathrm{CH}_{2} \mathrm{NMe}_{3}{ }^{+}$placed on the ortho position. We chose this group in place of $\mathrm{NH}_{3}{ }^{+}$ to avoid interference from hydrogen bonding. Unfortunately, the steric effects from the $\mathrm{CH}_{2}$-linker bent the phenyl out of the plane, inhibiting resonance. As a result, the gasphase barrier $\left(137 \mathrm{~kJ} \mathrm{~mol}^{-1}\right)$ was only marginally better than the para-substituted species $\left(143 \mathrm{~kJ} \mathrm{~mol}^{-1}\right)$, and not as good as replacing the $\mathrm{N}$-phenyl altogether with $\mathrm{CH}_{2} \mathrm{NH}_{3}{ }^{+}(118 \mathrm{~kJ}$ $\left.\mathrm{mol}^{-1}\right)$. Likewise, in the 2,5-diphenyl-tetrazole, inclusion of an ortho- $\mathrm{CH}_{2} \mathrm{BF}_{3}{ }^{-}$group on the $\mathrm{C}$-phenyl gives a barrier (144 $\mathrm{kJ} \mathrm{mol}^{-1}$ ) marginally better than the para-position (154 kJ $\mathrm{mol}^{-1}$ ) but worse replacing the phenyl with a $\mathrm{CH}_{2} \mathrm{BF}_{3}{ }^{-}(131 \mathrm{~kJ}$ $\left.\mathrm{mol}^{-1}\right)$.

Thus, it appears that the $2-\mathrm{CH}_{2} \mathrm{NH}_{3}{ }^{+}-5$-methyl-tetrazole represents a limit for electrostatic activation in this study. The barrier-lowering strategy itself could easily be generalized by using other positive CFGs. Because the CFG interacts electrostatically, it can be incorporated into more complex tetrazoles provided distance and orientation remain optimized, and direct conjugation of the CFG and reaction center is avoided. Because it is a through space-effect, CFGs can also be incorporated into an external catalyst, analogous to our work with Diels-Alder reactions. ${ }^{31}$ Alternatively metal complexation is another potential strategy to harness these electrostatic effects, and in this respect we note that Lewis acid complexation has been used to increase the rate of the reverse reaction, ${ }^{34}$ and the associated transition state stabilization would also increase the forward reaction. Finally, we note that, combinations of CFGs and other barrier-lowering 
strategies could yield further improvements in rate. In this respect we note that fluorine substitution and associated increases in heavy atom tunneling has been shown to enhance the rate of the reverse (and hence forward) reactions. ${ }^{41}$

\section{CONCLUSION}

While tetrazoles can undergo photochemical ring opening to form nitrile imines, thermally this requires temperatures of the order of $200{ }^{\circ} \mathrm{C}$ or more. Here we show that inclusion of non-conjugated charged functional group, can dramatically lower their ring opening barriers to the extent that their half-life in refluxing o-xylene decreases from 300,000 years to 1 week. Decreases in the gas-phase are even more dramatic, and lead to a half-life of seconds at the same temperature. Due to the developing dipole in the transition state, the barrier is lowered by positively charged groups on the $\mathrm{N}$-substituent and negatively charged groups on the C-substituent; smaller opposite effects are observed when the charged groups are reversed. Generally, substitution of a methyl, rather than a phenyl is more effective due to alignment with and proximity to the developing dipole. Because the effects presented here are electrostatic in origin, they can be generalized to other charged functional groups according synthetic constraints, and could also be combined with more traditional substituent effects to further lower reaction barriers.

\section{COMPUTATIONAL METHODS}

All calculations were performed using the M06-2X functional ${ }^{42}$ and $6-31+G(d, p)$ basis set with the $S M D{ }^{43}$ solvent model. This level of theory has previously been shown to provide highly accurate predictions of electrostatic effects (from remote charged functional groups and external electric fields) on barriers and reaction energies. ${ }^{27,} 29$ Wavefunction stability analysis was performed to confirm that the species were all closed shell and not open-shell singlets. All geometries were confirmed to be local minima (possessing no imaginary frequencies) or transition structures (possessing a single imaginary frequency), and where relevant complete conformational searches were performed at the same level of theory and based Gibbs free energies in solution. Gibbs free energies were obtained via a thermocycle in which the gas-phase entropies and thermal corrections were calculated using the ideal gas partition functions. Frequencies were scaled by the recommended scale factors. ${ }^{44}$ All calculations were carried out using Gaussian 16.C01. ${ }^{45}$

\section{ASSOSCIATED CONTENT}

\section{Supporting Information}

Complete computational details. The Supporting Information is available free of charge on the ACS Publications website.

\section{Corresponding Author}

*Email: michelle.coote@anu.edu.au

\section{Current Address}

†School of Engineering, RMIT University, Melbourne, Victoria 3001, Australia

\section{ACKNOWLEDGMENTS}

The authors acknowledge financial support from the Australian Research Council (ARC) Centre of Excellence for Electromaterials Science (CE140100012), an ARC Laureate Fellowship (to M.L.C.; FL170100041,), and generous supercomputing time from the National Computational Infrastructure.

\section{REFERENCES}

1. Li, J.; Wang, J.; Chen, X.; LV, Z.; Chen, T.; Wang, T., A highly conductive proton exchange membrane for high temperature fuel cells based on poly(5-vinyl tetrazole) and sulfonated polystyrene. Solid State Ion. 2014, 255, 128-134.

2. Secci, F.; Arca, M.; Frongia, A.; Piras, P. P., Tetrazole amides as hydrogen-bonding donor catalysts in the chemoselective oxidation of sulphides and disulphides. Catal. Sci. Technol. 2014, 4, 1407-1415.

3. Biot, C.; Bauer, H.; Schirmer, R. H.; Davioud-Charvet, E., 5-Substituted Tetrazoles as Bioisosteres of Carboxylic Acids. Bioisosterism and Mechanistic Studies on Glutathione Reductase Inhibitors as Antimalarials. J. Med. Chem. 2004, 47, 5972-5983.

4. Ostrovskii, V. A.; Popova, E. A.; Trifonov, R. E., Chapter One - Developments in Tetrazole Chemistry (2009-16). In Advances in Heterocyclic Chemistry, Scriven, E. F. V.; Ramsden, C. A., Eds. Academic Press: 2017; Vol. 123, pp 1-62.

5. Ajay Kumar, K.; Govindaraju, M.; Vasanth Kumar, G., ChemInform Abstract: Nitrile Imines: Versatile Intermediates in the Synthesis of Five Membered Heterocycles. 2014, 45.

6. Huisgen, R.; Seidel, M.; Wallbillich, G.; Knupfer, H., Diphenyl-nitrilimin und seine 1.3-dipolaren additionen an alkene und alkine. Tetrahedron 1962, 17, 3-29.

7. Clovis, J. S.; Eckell, A.; Huisgen, R.; Sustmann, R., 1.3Dipolare Cycloadditionen, XXV. Der Nachweis des freien Diphenylnitrilimins als Zwischenstufe bei Cycloadditionen. Chem. Ber. 1967, 100, 60-70.

8. Ostrovskii, V. A.; Koldobskii, G. I.; Trifonov, R. E., 6.07 Tetrazoles. In Comprehensive Heterocyclic Chemistry III, Katritzky, A. R.; Ramsden, C. A.; Scriven, E. F. V.; Taylor, R. J. K., Eds. Elsevier: Oxford, 2008; pp 257-423.

9. Manelis, G., Thermal Decomposition and Combustion of Explosives and Propellants. . CRC Press, : London, 2003. 
10. Kiselev, V. G.; Cheblakov, P. B.; Gritsan, N. P., Tautomerism and Thermal Decomposition of Tetrazole: High-Level ab Initio Study. J. Phys. Chem. A 2011, 115, 1743-1753.

11. Wentrup, C.; Fischer, S.; Maquestiau, A.; Flammang, R., Nitrile Imines: Thermal Generation, Direct Observation, and Subsequent Trapping. Angew. Chem. Int. Ed. 1985, 24, 56-57.

12. Lesnikovich, A. I.; Levchik, S. V.; Balabanovich, A. I.; Ivashkevich, O. A.; Gaponik, P. N., The thermal decomposition of tetrazoles. Thermochim. Acta 1992, 200, 427-441.

13. Bégué, D.; Qiao, G. G.; Wentrup, C., Nitrile Imines: Matrix Isolation, IR Spectra, Structures, and Rearrangement to Carbodiimides. J. Am. Chem. Soc. 2012, 134, 5339-5350.

14. Bégué, D.; Santos-Silva, H.; Dargelos, A.; Wentrup, C., ImidoyInitrenes $\mathrm{R}^{\prime} \mathrm{C}(=\mathrm{NR})$ - N, Nitrile Imines, $1 \mathrm{H}$-Diazirines, and Carbodiimides: Interconversions and Rearrangements, Structures, and Energies at DFT and CASPT2 Levels of Theory. J. Phys. Chem. A 2017, 121, 8227-8235.

15. Menzel, J. P.; Noble, B. B.; Lauer, A.; Coote, M. L.; Blinco, J. P.; Barner-Kowollik, C., Wavelength Dependence of LightInduced Cycloadditions. Journal of the American Chemical Society 2017, 139, 15812-15820.

16. Estupiñán, D.; Gegenhuber, T.; Blinco, J. P.; BarnerKowollik, C.; Barner, L., Self-Reporting Fluorescent Step-Growth RAFT Polymers Based on Nitrile Imine-Mediated Tetrazole-ene Cycloaddition Chemistry. ACS Macro Lett. 2017, 6, 229-234.

17. Lederhose, P.; Abt, D.; Welle, A.; Müller, R.; BarnerKowollik, C.; Blinco, J. P., Exploiting $\lambda$-Orthogonal Photoligation for Layered Surface Patterning. Chem. Eur. J. 2018, 24, 576-580.

18. Vonhören, B.; Roling, O.; Buten, C.; Körsgen, M.; Arlinghaus, H. F.; Ravoo, B. J., Photochemical Microcontact Printing by Tetrazole Chemistry. Langmuir 2016, 32, 2277-2282.

19. Song, W.; Wang, Y.; Qu, J.; Madden, M. M.; Lin, Q., A Photoinducible 1,3-Dipolar Cycloaddition Reaction for Rapid, Selective Modification of Tetrazole-Containing Proteins. Angew. Chem. Int. Ed. 2008, 47, 2832-2835.

20. Herner, A.; Lin, Q., Photo-Triggered Click Chemistry for Biological Applications. Top. Curr. Chem. 2016, 374, 1.

21. Nájera, C.; Sansano, J. M.; Yus, M., 1,3-Dipolar cycloadditions of azomethine imines. Org. Biomol. Chem. 2015, 13, 8596-8636.

22. Shaik, S.; Ramanan, R.; Danovich, D.; Mandal, D., Structure and reactivity/selectivity control by oriented-external electric fields. Chem. Soc. Rev. 2018, 47, 5125-5145.

23. Ciampi, S.; Darwish, N.; Aitken, H. M.; Diez-Perez, I.; Coote, M. L., Harnessing electrostatic catalysis in single molecule, electrochemical and chemical systems: a rapidly growing experimental tool box. Chem. Soc. Rev. 2018, 47, 5146-5164.

24. Shaik, S.; Mandal, D.; Ramanan, R., Oriented electric fields as future smart reagents in chemistry. Nat. Chem. 2016, 8, 1091-1098.

25. Gryn'ova, G.; Smith, L. M.; Coote, M. L., Computational design of $\mathrm{pH}$-switchable control agents for nitroxide mediated polymerization. Phys. Chem. Chem. Phys. 2017, 19, 22678-22683.

26. Klinska, M.; Smith, L. M.; Gryn'ova, G.; Banwell, M. G.; Coote, M. L., Experimental demonstration of pH-dependent electrostatic catalysis of radical reactions. Chem. Sci. 2015, 6, 56235627.

27. Gryn'ova, G.; Marshall, D. L.; Blanksby, S. J.; Coote, M. L., Switching radical stability by $\mathrm{pH}$-induced orbital conversion. Nat. Chem. 2013, 5, 474.
28. Meir, R.; Chen, H.; Lai, W.; Shaik, S., Oriented Electric Fields Accelerate Diels-Alder Reactions and Control the endo/exo Selectivity. ChemPhysChem 2010, 11, 301-310.

29. Aragones, A. C.; Haworth, N. L.; Darwish, N.; Ciampi, S.; Bloomfield, N. J.; Wallace, G. G.; Diez-Perez, I.; Coote, M. L., Electrostatic catalysis of a Diels-Alder reaction. Nature 2016, 531, 88-91.

30. Blyth, M. T.; Noble, B. B.; Russell, I. C.; Coote, M. L., Oriented Internal Electrostatic Fields Cooperatively Promote Ground- and Excited-State Reactivity: A Case Study in Photochemical CO2 Capture. J. Am. Chem. Soc. 2020, 142, 606-613. 31. Blyth, M. T.; Coote, M. L., A pH-Switchable Electrostatic Catalyst for the Diels-Alder Reaction: Progress toward Synthetically Viable Electrostatic Catalysis. J. Org. Chem. 2019, 84, 1517-1522.

32. Aitken, H. M.; Coote, M. L., Can electrostatic catalysis of Diels-Alder reactions be harnessed with $\mathrm{pH}$-switchable charged functional groups? Phys. Chem. Chem. Phys. 2018, 20, 1067110676.

33. Bhattacharyya, K.; Karmakar, S.; Datta, A., External electric field control: driving the reactivity of metal-free azidealkyne click reactions. Phys. Chem. Chem. Phys. 2017, 19, 2248222486.

34. Montero-Campillo, M. M.; Alkorta, I.; Elguero, J., Activation of Dinitrogen as A Dipolarophile in 1,3-Dipolar Cycloadditions: A Theoretical Study Using Nitrile Imines as "Octet" 1,3-Dipoles. Sci. Rep. 2017, 7, 6115.

35. Hill, N. S.; Coote, M. L., Internal Oriented Electric Fields as a Strategy for Selectively Modifying Photochemical Reactivity. J. Am. Chem. Soc. 2018, 140, 17800-17804.

36. Gryn'ova, G.; Coote, M. L., Origin and Scope of LongRange Stabilizing Interactions and Associated SOMO-HOMO Conversion in Distonic Radical Anions. J. Am. Chem. Soc. 2013, 135, 15392-15403

37. Gryn'ova, G.; Coote, M. L., Directionality and the Role of Polarization in Electric Field Effects on Radical Stability. Aust. J. Chem. 2017, 70, 367-372.

38. Bégué, D.; Wentrup, C., Carbenic Nitrile Imines: Properties and Reactivity. J. Org. Chem. 2014, 79, 1418-1426.

39. Mawhinney, R. C.; Muchall, H. M.; Peslherbe, G. H., The electronic structure of nitrilimines revisited. Chem. Commun. 2004, 1862-1863.

40. Mawhinney, R. C.; Peslherbe, G. H.; Muchall, H. M., Characterizing Nitrilimines with Nuclear Magnetic Resonance Spectroscopy. A Theoretical Study. J. Phys. Chem. B 2008, 112, 650655.

41. Karmakar, S.; Datta, A., Metal Free Azide-Alkyne Click Reaction: Role of Substituents and Heavy Atom Tunneling. J. Phys. Chem. B 2015, 119, 11540-11547.

42. Zhao, Y.; Truhlar, D. G., The M06 suite of density functionals for main group thermochemistry, thermochemical kinetics, noncovalent interactions, excited states, and transition elements: two new functionals and systematic testing of four M06class functionals and 12 other functionals. Theor. Chem. Acc. 2008, 120, 215-241.

43. Marenich, A. V.; Cramer, C. J.; Truhlar, D. G., Universal Solvation Model Based on Solute Electron Density and on a Continuum Model of the Solvent Defined by the Bulk Dielectric Constant and Atomic Surface Tensions. J. Phys. Chem. B 2009, 113, 6378-6396.

44. Alecu, I. M.; Zheng, J.; Zhao, Y.; Truhlar, D. G., Computational Thermochemistry: Scale Factor Databases and 
Scale Factors for Vibrational Frequencies Obtained from Electronic Model Chemistries. J. Chem. Theory Comput. 2010, 6, 2872-2887.

45. Frisch, M. J.; Trucks, G. W.; Schlegel, H. B.; Scuseria, G.

E.; Robb, M. A.; Cheeseman, J. R.; Scalmani, G.; Barone, V.;
Petersson, G. A.; Nakatsuji, H., et al. Gaussian 09 Rev. C.01, Wallingford, CT, 2016. 
Table of contents graphic

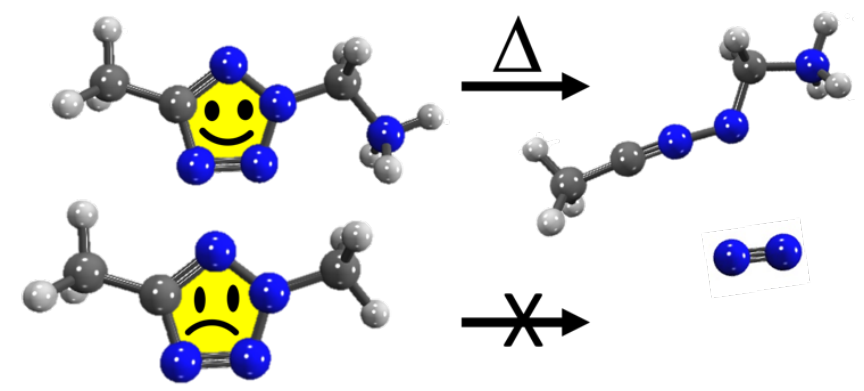

10 